
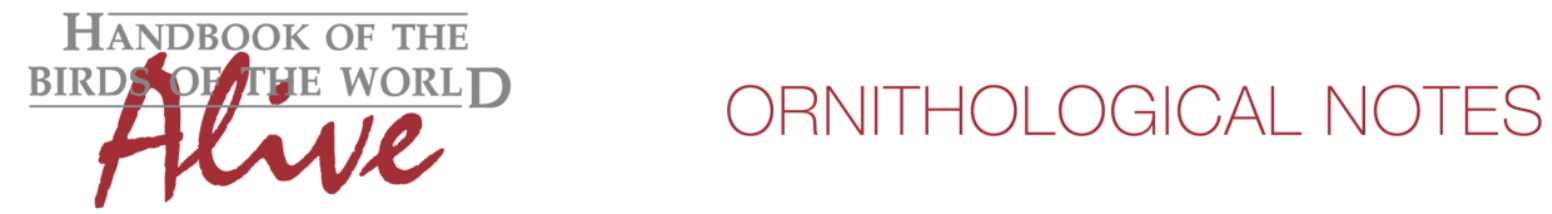

\title{
Notes on the vocalizations of Monk Parakeet (Myiopsitta monachus) and Cliff Parakeet (Myiopsitta Iuchsi)
}

Peter Boesman

In the following text, I briefly analyze and compare the voices of Monk Parakeet (Myiopsitta monachus) and Cliff Parakeet (Myiopsitta luchsi). I also try to quantify the extent of any vocal differences using the criteria proposed by Tobias et al. (2010), as a basis for taxonomic review. I have made use of sound recordings available online at Xeno Canto $(X C)$ and the Macaulay Library (ML).

Cliff Parakeet M. Iuchsi was only recently elevated to species rank (del Hoyo \& Collar 2014), mainly based on differences in plumage and breeding habits. However, to date not all taxonomic lists have followed such treatment.

The voice of both species has never been compared in depth, although vocal differences were noted already by Lane (2011), who indicated that recordings of Cliff Parakeet sound consistently higher-pitched, less grating, and generally shorter in duration than Monk Parakeet.

Based on available recordings (excluding feral populations), the vocabulary of both species can be described as follows.

\section{Monk Parakeet $M$. monachus}

The most common call is a low-pitched grating drawn-out "rrreh" typically repeated many times (Fig. 1). In the large majority of recordings ( $n=60)$, voice consisted exclusively of such notes, or such notes were at least present.

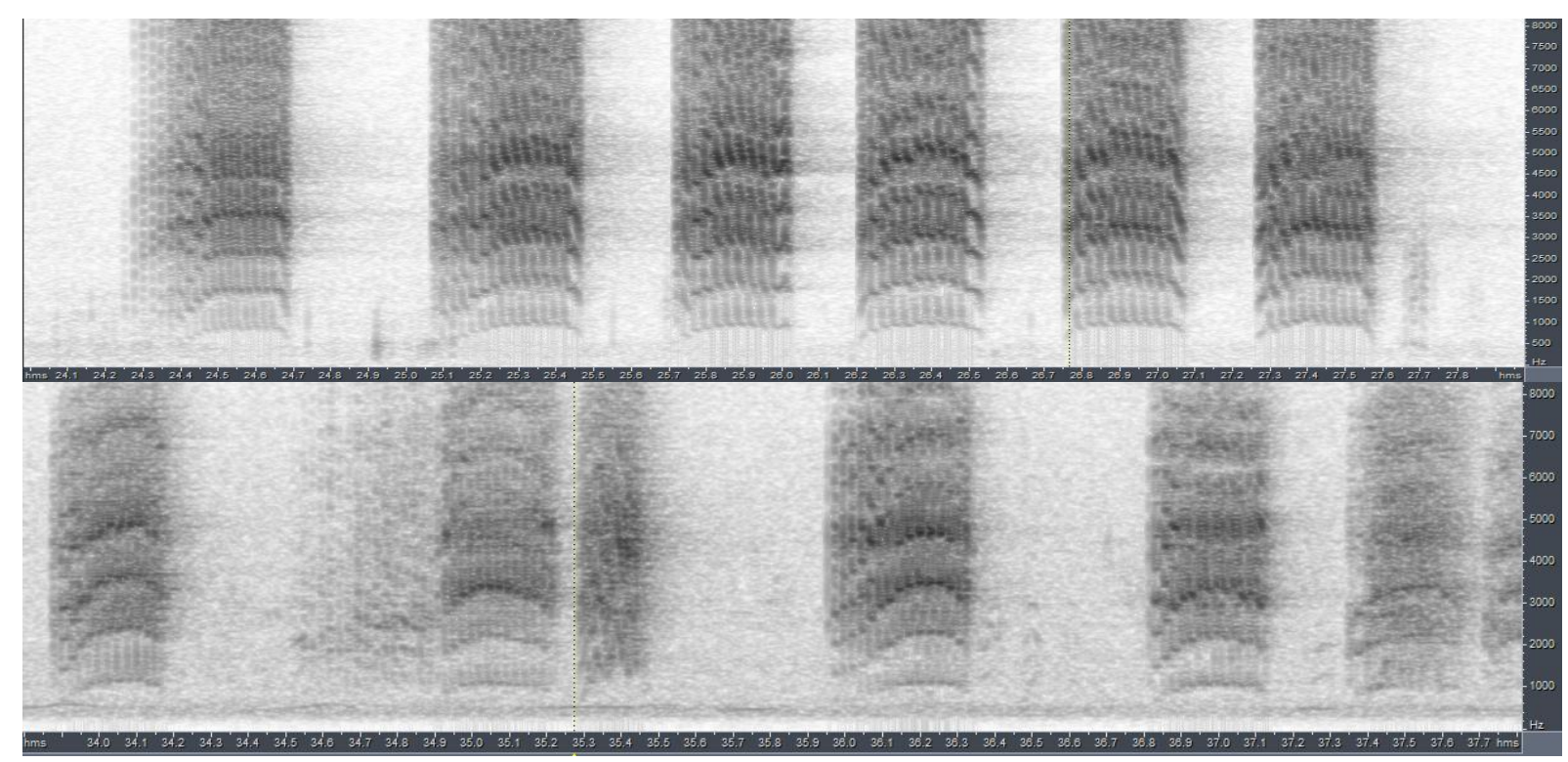



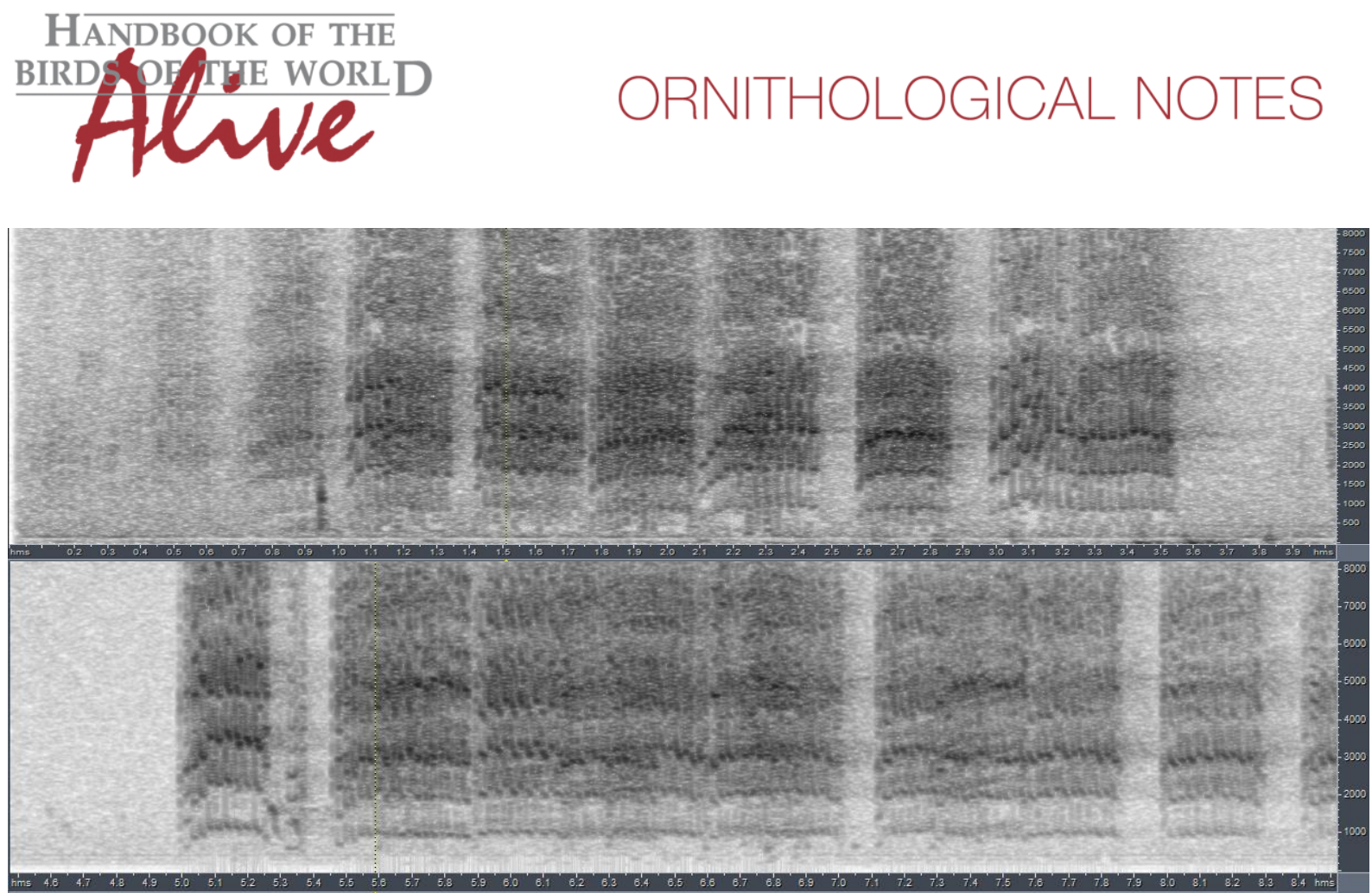

Fig. 1. From top to bottom: examples from far-flung localities in the range of Monk Parakeet M. monachus: ML212802: Formosa, Argentina, Juan Areta; XC272942: Cordoba, Argentina, Peter Boesman; XC211539: Rio Grande do Sul, Brazil, Fernando Igor de Godoy; XC87926: Santa Cruz, Bolivia, Daniel Lane.

Other vocalizations given when perched or near the nest are all typically shorter in duration and include a variety of screeches, churrs and squawks, typically in a squabbling 'conversation' (Fig. 2).

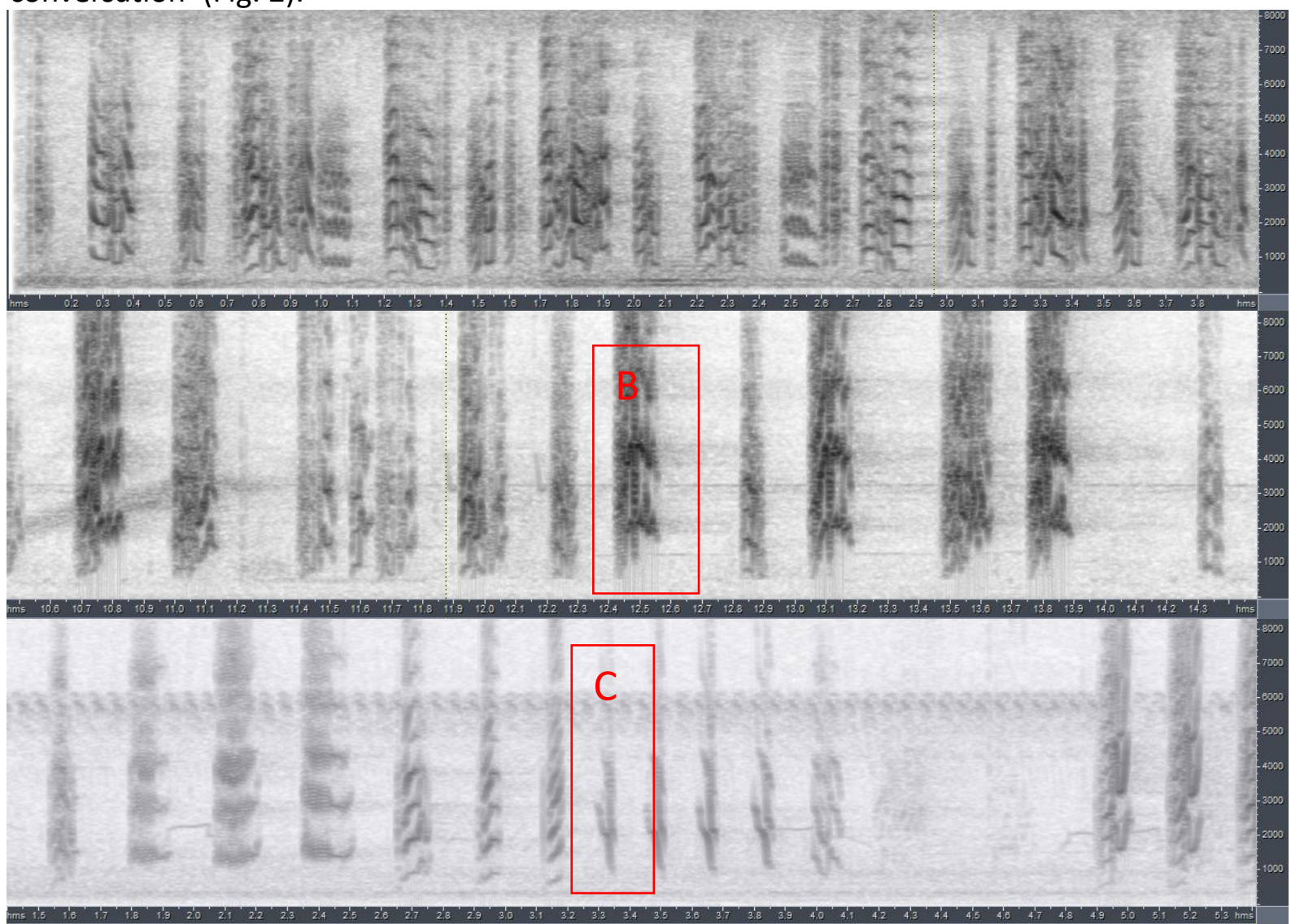

Fig. 2. From top to bottom: other vocalizations of Monk Parakeet M. monachus: XC196520: Mato Grosso do Sul, Brazil, Gabriel Rosa; XC116252: Mato Grosso, Brazil, Andrew Spencer; XC85235: Rio Grande do Sul, Brazil, Jeremy Minns. 

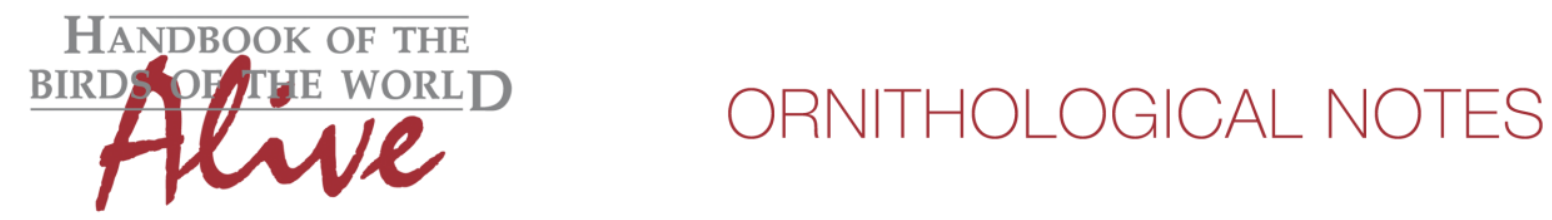

\section{Cliff Parakeet M. luchsi}

There are many fewer recordings available of this taxon $(n=12)$. In six recordings we can hear a strident "kweeh!" (Fig. 3).

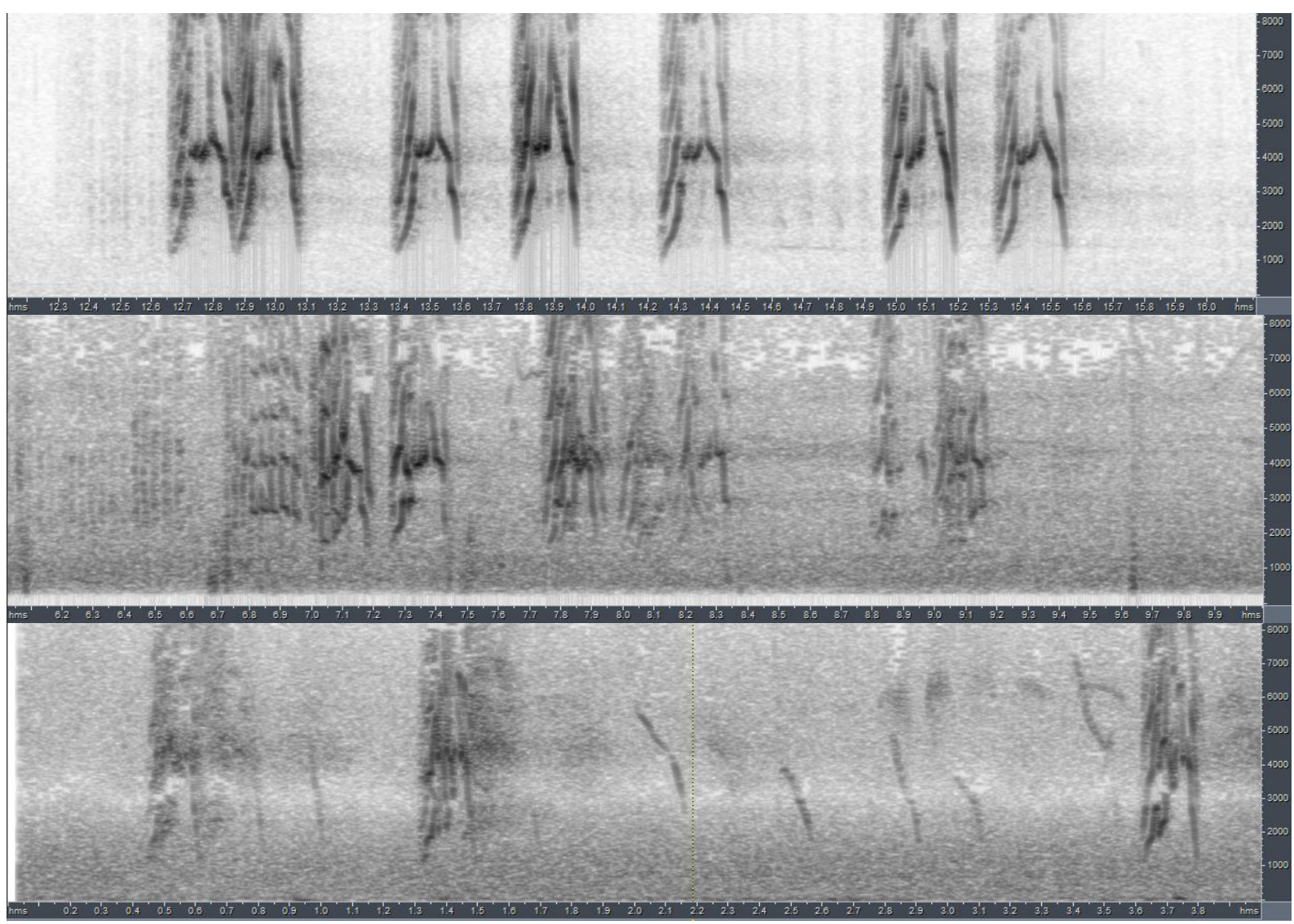

Fig. 3. From top to bottom: typical call of Cliff Parakeet M. Iuchsi: XC189899: Santa Cruz, Bolivia, Andrew Spencer; XC87929: Santa Cruz, Bolivia, Daniel Lane; XC16180: Bolivia, Niels Krabbe.

Other vocalizations include (fig.4): A: a grating drawn-out rattle quite similar to $M$. monachus (but only uttered very occasionally and sounding slightly higher-pitched); B: a short rising grating note; and C: a short downslurred note.

The vocabulary of both species thus shows some similarities (especially in conversational calls when perched) as can be expected in closely related parrot species. It would seem, however, that $M$. luchsi has a unique high-pitched call, uttered very frequently, with a maximum frequency much higher than any vocalization of $M$. monachus (maximum base frequency ranging from c. $5 \mathrm{kHz}$ to $7 \mathrm{kHz}$, while maximum frequency of all vocalizations of $M$. monachus typically remains below $3 \mathrm{kHz}$ ). M. monachus on the other hand mainly utters the drawn-out grating call, which seems to be a much less important call in M. luchsi. 


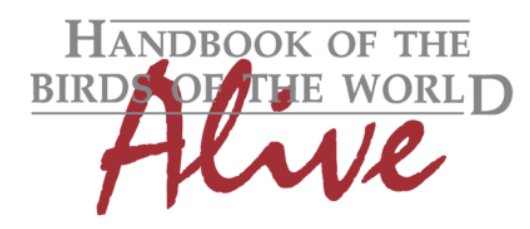

\section{ORNITHOLOGICAL NOTES}

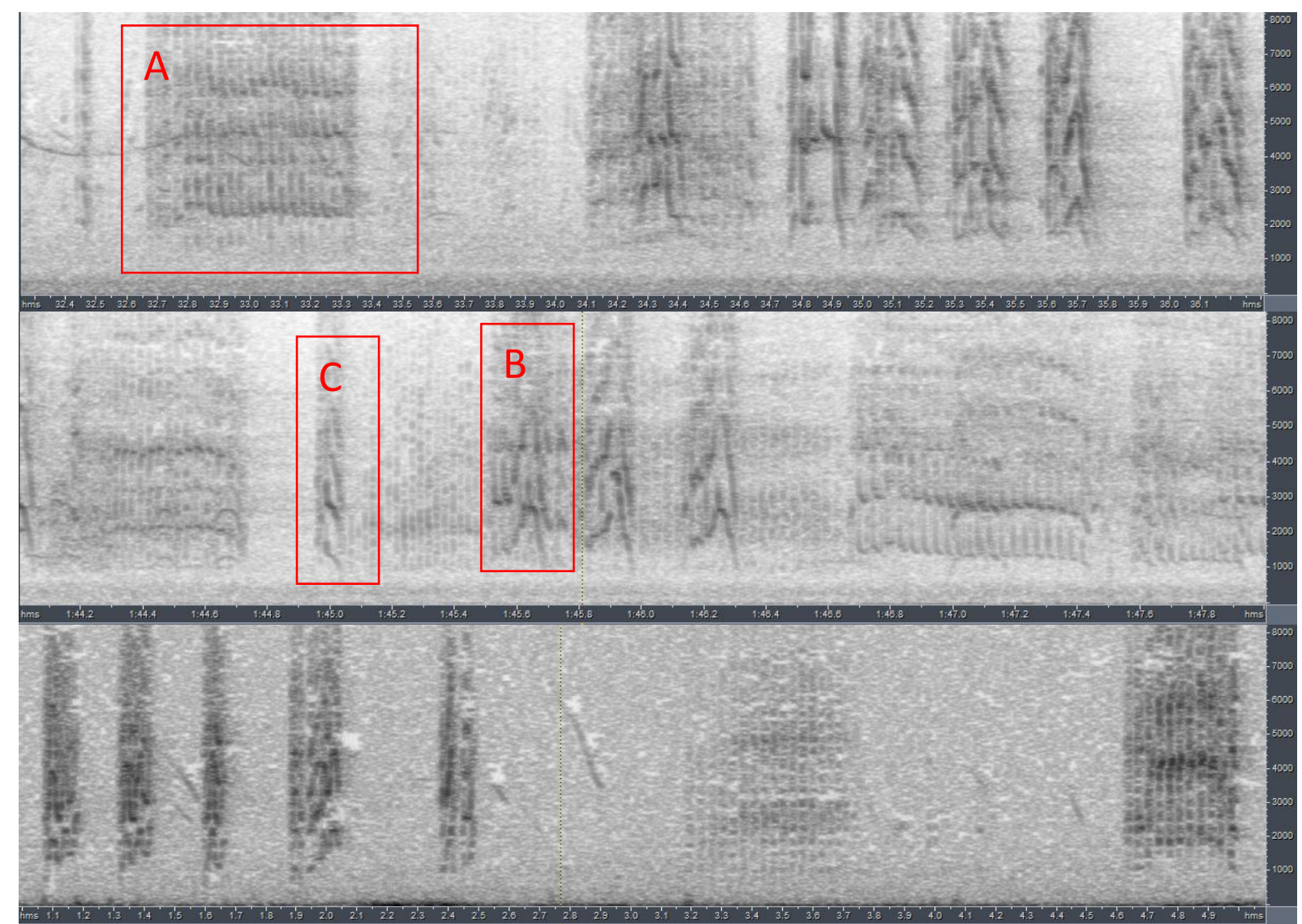

Fig. 4. From top to bottom: other vocalizations of Cliff Parakeet M. luchsi: ML132540: Cochabamba, Bolivia, Peter Hosner; ML132538: Cochabamba, Bolivia, Peter Hosner; XC4416: Bolivia, Sebastian Herzog.

These vocal differences can be quantified either by comparing maximum frequency of calls (score 3) or mean frequency of all vocalizations (2-3). Furthermore, even call notes that are shared by species, but are uttered at a very different rate represent an additional important differentiator (e.g. such a character was a major element to support splitting Sirystes Sirystes sibilator into four species). Total vocal score thus is (at least) 3.

I conclude that the voices of Monk Parakeet and Cliff Parakeet show some clear differences, further supporting their treatment as two species.

This note was finalized on 21st May 2017, using sound recordings available online at that time. I thank, in particular, the many sound recordists who made their recordings of this species available on XC and ML, and Guy Kirwan for revising the original text.

\section{References}

del Hoyo, J. \& Collar, N.J. (2014) HBW and Birdlife International Illustrated Checklist of the Birds of the World. Vol. 1. Non-passerines. Lynx Edicions. Barcelona.

Lane, D. (2011) Treat Myiopsitta luchsi as a separate species from M. monachus. Proposal 503 to the South American Classification Committee.

http://www.museum.Isu.edu/ Remsen/SACCprop503.htm

Tobias, J.A., Seddon, N., Spottiswoode, C.N., Pilgrim, J.D., Fishpool, L.D.C. \& Collar, N.J. (2010) Quantitative criteria for species delimitation. Ibis 152(4): 724-746. 


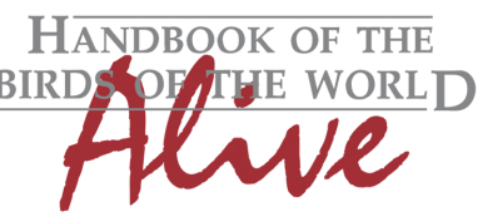

\section{ORNITHOLOGICAL NOTES}

\section{Recommended citation}

Boesman, P. (2017) Notes on the vocalizations of Monk Parakeet (Myiopsitta monachus) and Cliff Parakeet (Myiopsitta luchsi). HBW Alive Ornithological Note 452. In: Handbook of the Birds of the World Alive. Lynx Edicions, Barcelona. (retrieved from http://www.hbw.com/node/931753 on 21 May 2017). 